\title{
Free Open Source Software: FOSS Based e-learning, Mobile Learning Systems Together with Blended Learning System
}

\author{
Kohei Arai ${ }^{1}$ \\ ${ }^{1}$ Graduate School of Science and Engineering \\ Saga University \\ Saga City, Japan
}

\begin{abstract}
Free Open Source Software: FOSS based elearning system is proposed together with blended learning and mobile learning. Mashup search engine for e-learning contents search and content adaptation from e-learning to mobile learning content are also implemented. Through implementation of the proposed system, it is found that the system does work well for improvement of learning efficiency.
\end{abstract}

Keywords-e-learning; blended learning; foree open source softeware; mushup; mobile learning

\section{INTRODUCTION}

Free Open Source Software: FOSS is getting popular now a day very much and is widely available for e-learning, blended learning and mobile-learning [1]-[12]. All the required components for creation of e-learning system can be created with FOSS software.

Comprehensive economy framework among ASEANJapan agreed in April 2003 emphasizes ICT related Human Resource. Concentrating realistic manner for creation of elearning, m-learning contents, the tools, Moodle, apache, php, SQL, video streaming, Perl, blended learning, chat-bot, camera monitor, etc. are provided. Methods for contents creation for math., object oriented language, etc. subjects: Concentrate how to teach and learn, how to improve students' capability $=$ FD. Content adaptation from e-learning to mlearning is also available together with Mashup contents search, AdHoc mesh network.

Japanese contribution on ICT technology to Asian countries, in terms of ICT infrastructure, ICT technology for higher education, Preparation of e-learning, m-learning content creations, Sharing contents are enhanced. Meanwhile, Web2.0 is getting popular and is widely used. In particular, Extensible Markup Language (XML), Simple Object Access Protocol (SOAP), Web Services Description Language (WSDL), Universal Description, Discovery, and Integration (UDDI), Social Networking Sites, Aggregators, Mashups are getting popular.

On the other hand, M-learning is widely used now a day. Because it is highly portable, available wherever the user needs to learn, individual, adapting to the learner's abilities, unobtrusive, the learner can capture situations and retrieve knowledge without the technology obtruding on the situation; available anywhere, to enable communication with teachers, experts and peers. Also it is adaptable, to the context of learning and the learner's evolving skills and knowledge; persistent, to manage learning throughout a lifetime, useful, suited to everyday needs for communication, reference, work and learning, easy to use, by people with no previous experience of the technology.

The system proposed here is FOSS based e-learning and mobile learning systems together with blended learning. It can be created with free open source software with PC which is getting much cheaper than before. Therefore, it requires a small amount of money while performance and capability is almost compatible to the conventional expensive system.

The following section describes the proposed system followed by some experiments on blended learning which shows an effectiveness of blended learning. Then conclusion is described together with some discussions,

\section{PROPOSED SYSTEM}

\section{A. Free Open Sorce Software: FOSS}

A variety of software is available as FOSS. The followings are just examples for FOSS. All the required modules for elearning, blended learning and mobile learning systems can be created with FOSS

- Operating System: OS

Linux OS is freely available from the following site,

$$
\text { - Linux: http://www.linux.org/ }
$$

- Database: DB

Database handling and processing can be done with PostgreSQL, MySQL, etc. which are available from the following sites,

$$
\begin{array}{ll}
\text { - } & \text { PostgreSQL: http://www.postgresql.org/ } \\
\text { - } & \text { MySQL: }
\end{array}
$$

- Web design

e-learning, blended learning, mobile learning systems need web design and network control. Web design and networking 
FOSS is available. For instance, JBOSS Tomcat of web design and networking FOSS is available from the following site,

$$
\begin{aligned}
& \text { - JBOSS Tomcat: } \\
& \text { http://openstandia.jp/services/jboss/jboss_ba } \\
& \text { sic_performance.html }
\end{aligned}
$$

Other than this, there is available JBOSS EAP and the other following functions of FOSS,

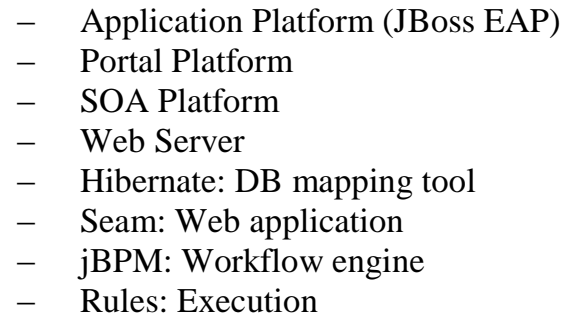

- Network Management

Network management of FOSS is also available. For instance, Hinemos can be downloading from the following site,

- Hinemos: http://sourceforge.jp/projects/hinemos/

The following functions are provided by the Hinemos,

- Efficient management and operation

- Log check

- Performance check

- Job execute

- Configuration management

- Batch processing

- Web server

- Network devices

- DB server

- AP server

- Programming

Ruby, Perl are typical programming languages and are downloaded from the following sites,

- Ruby: http://www.ruby-lang.org/en/

- Perl: http://www.perl.org/

- Office like application

Office like application FOSS is available from the following site,

- StarSuite: http://www.openoffice.org/

Word processing, table calculation, etc. Can be done with the StarSuite of FOSS

\section{- Web Browser}

Web browsing can be done with FOSS of Mozilla FireFox which can be downloaded from the following site,

- Mozilla FireFox: http://www.mozilas.com/
More important core software of Learning Management System of FOSS is available. As mentioned previously, SCORM standard is the key issues here in e-learning, blended learning, mobile learning systems. If the systems and created e-learning contents meet with all the required specifications of SCORM standard, then the systems can share the e-learning contents. One of SCORM standard of FOSS is Moodle followed by Attain. Moodle and Attain can be downloaded from the following sites,

$$
\begin{array}{ll}
\text { - } & \text { SCORM, Moodle, etc: } \\
\text { http://satt.jp/product/attain3/download.htm } \\
\text { - } & \text { http://moodle.org/downloads/ }
\end{array}
$$

- Open Simulator for chatting (Second Life)

Chatting function can be created by using Open Simulator attractively. One of the examples of chatting capability included e-learning system is proposed already. Open Simulator can be downloaded from the following site,

http://opensimulator.org/wiki/Main_Page

By using the aforementioned FOSS software, all the components required for construction of e-learning system, blended learning, and mobile learning system can be created.

\section{B. Conventional e-learning system}

Conventional e-learning system is matched with SCORM1.2, SCORM2004 standard $^{1}$. The followings are important for Learning Management System; LMS of the SCORM standard,

- reusability

- accessibility

- durability

- interoperability

Learnt information can be gathered through API adapter program. Content aggregation can be done with the followings,

- XML file with keywords, version, provider name, etc.

- $\mathrm{XML}+$ contents $\rightarrow$ ZIP

- Stored in LMS

Therefore, learnt information can be referred by all the students and the lecturers through Moodle.

\section{Blended Learning System}

Blended Learning is the way to teach and to learn through combination or 'blending' of multiple methods and learning styles together. Typical Blended Learning is based on the combination of online and face-to-face basis approaches for teach and learn. It is possible to provide flexible and alternative learning opportunities for students even if students are out the classroom and if after class.

\footnotetext{
${ }^{1}$ http://203.183.1.152/cgi-bin/csvmail/kigyou_scorm_download.html
} 
To encourage learning, blended learning system can be used by students when students are out the classroom and when after school. In our face-to-face lecture, any e-learning system is used. Another example is a course which carries out alternately the face-to-face lecture and e-learning, m-learning.

Figure 1 shows a typical blended learning scheme. In a prior to start the class in concern, students can download the learning materials through e-learning system. After that, students have the class through face to face lectures with support from e-learning systems. Question and Answering system, chatting system, bulletin board system, and mobile learning system is used for students. After the class ends, students may learn about class subjects through e-learning and mobile learning systems.

\section{Classroom}

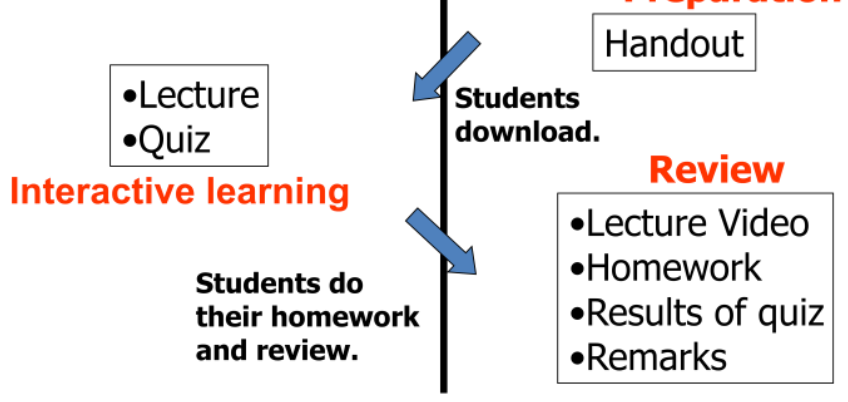

Fig. 1. Blended Learning Scheme

\section{Moodle system}

Moodle $^{2}$ is a widely used standard LMS of e-learning system. Example of my Moodle site in the Graduate School of Science and Engineering, Saga University is shown in Figure 2 .

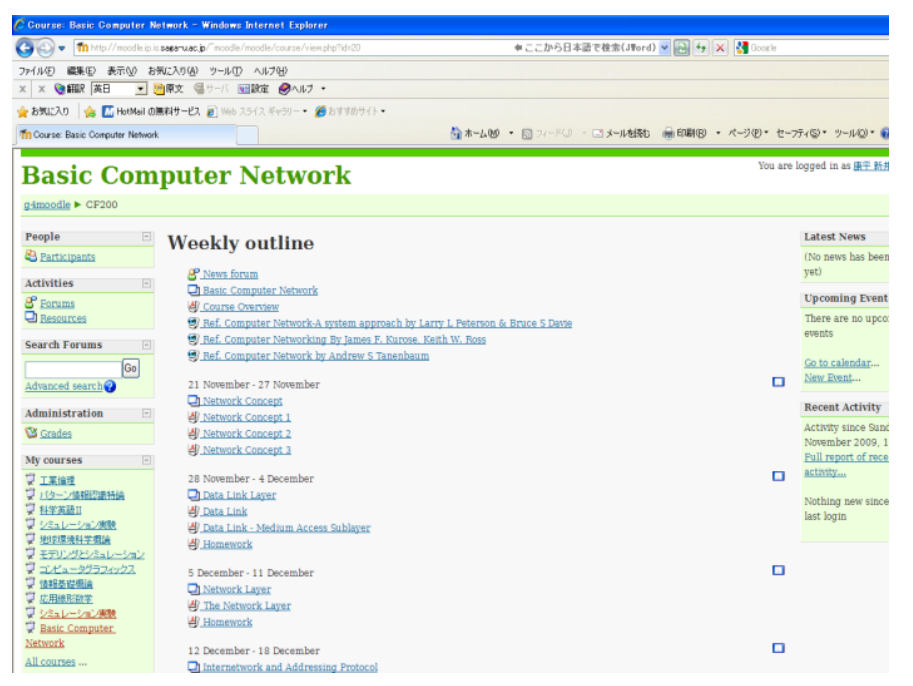

Fig. 2. Example of my Moodle site

\footnotetext{
${ }^{2}$ http://net.pd.saga-u.ac.jp/e-learning/
}

The URL for Saga University Moodle site is

http://net.pd.saga-u.ac.jp/e-learning/.

From the site, class related information, outline, schedule, contents, forum, Q/A, quiz, chat, achievement test are available. One month before class starts, this site has to be opened.

Contents resources archives are available from the following site, for example,

http://upo-net.code.u-air.ac.jp/about/

Open University in Japan creates ups of content database which allows download and retrieves Moodle contents.

\section{E. Lecture scenario creation and edit}

There are some software tools for lecture scenario creation and edit as follows,

- Basic HTML files

- Pages for state explanation and instruction and links for selections

- $\quad$ Free form

- Moodle's Lesson module: we can provide

- Provides standard actions for the transition

- Captivate(Adobe)

- Provides rich contents

Although the most recommendable software for scenario creation and editing is Captivate which is provided by Adobe, is can be done with basic html files and Moodle of FOSS. Captivate does cost.

Also lesson modules for Moodle are available as follows,

- Select "Lesson" from "Add an activity"

- Sample:

http://www.cs.is.sagau.ac.jp/\%7Emika/lecture/moodle/mod/lesson/view.php?id=24

- How to create it (SWF)

Small Web Format of files can be created easily. The following site provide a lesson learnt information,

http://www.cs.is.sagau.ac.jp/\% 7Emika/lecture/moodle/mod/resource/view.php?id=2 6

Captivate has a project type for a scenario base material. Software and scenario simulations are available. Scenario simulation provides branching functionality.

- Capturing mode usage: Recording

- Editing mode usage: Editing

- Exporting into a flash file: Publishing

- Objects: Text Caption, Rollover Caption, Highlighting 
Box, etc.

- Slides: Question Slide, Random Question Slide, Image Slide, etc.

- Timeline Editing

- Library Usage

- Branching

Scenario Simulation provides branching functionality as shown in Figure 3.

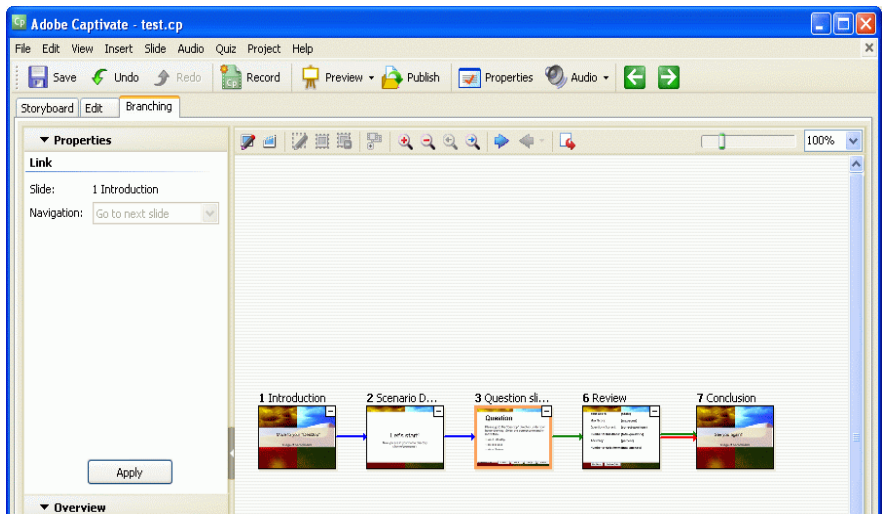

Fig. 3. branching function for scenario simulations

Scenario number can be rearranged by clinking the scenario block and drag and drop operation for replacing the scenario numbers easily.

\section{F. Image manipulation}

For creation of e-learning contents, image processing, capturing, processing, and output imagery data is needed. Green shot is an example of image manipulation software with the following functions.

- Simple screen shot tool for Windows

- Open Source (GPL)

- Current Version: Beta 6.0

- $\quad$ Requires .Net framework 2.0

- Still capture: region, window, full screen

- Simple editor: rectangle, oval, text area

- Several image formats: JPEG, GIF, PNG, BMP

- Weak points: no timer, no undo,

It is also available for the following edit and save the files.

- The built in image editor popped up after capturing automatically

- Add objects: rectangle, oval, textbox

- Image file formats: JPEG, GIF, PNG, BMP

- Try them all using the "Save as ..." menu

Irfan is the image manipulation software with the following functions,
You may convert from many kinds of still and moving picture formats to many kinds of formats

Figure 4 shows the available file formats which are supported by the Infan FOSS while Figure 4 shows the available image processing functions which are supported by Irfan FOSS software.

On the other hand, Irfan has many image processing capabilities as shown in Figure 5.

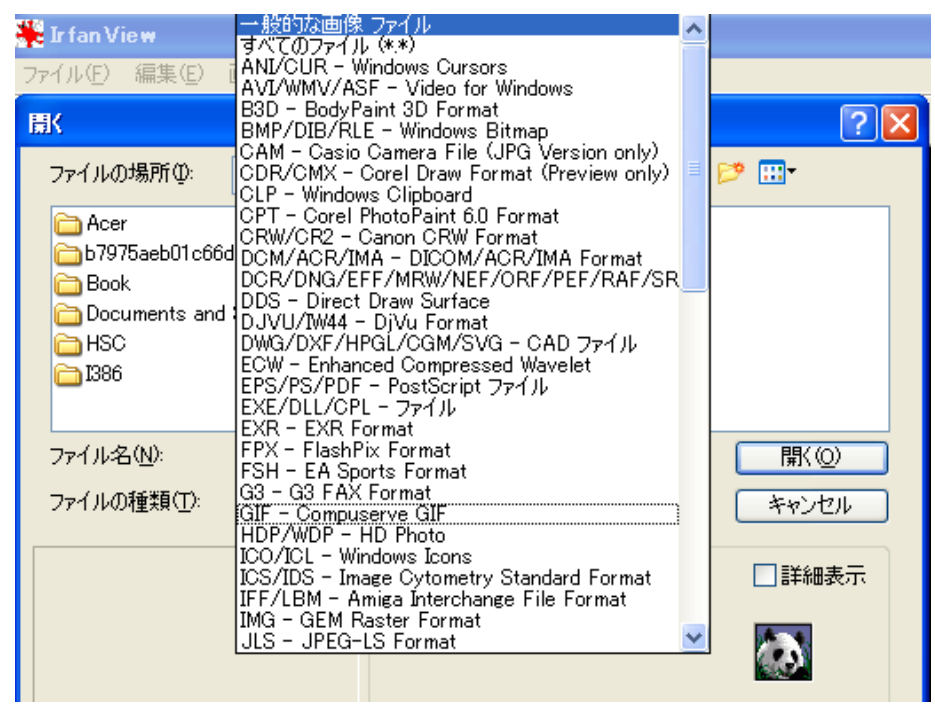

Fig. 4. Available file formats which is supported by Infan FOSS software

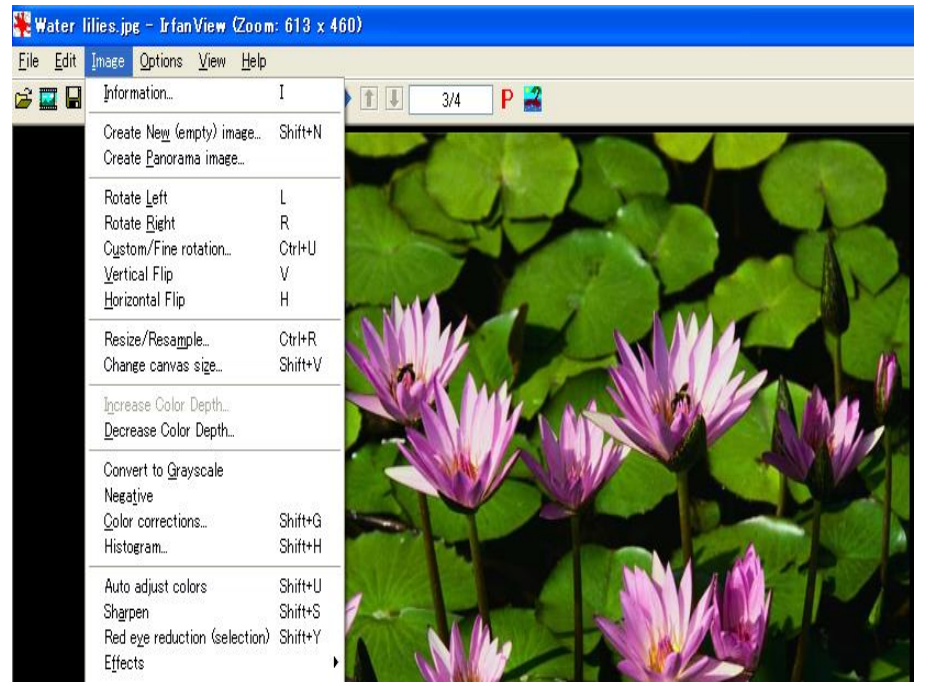

Fig. 5. Available functions which is supported by Irfan FOSS software.

\section{G. Video capture and editing}

Capture XP is the video capture and edits software with the following functions,

- Free but not open

- Japanese version only

- No built in viewer / editor

- Timer function
- Requires external viewer / editor 
Configuration of Capture XP has the following functions,

- Setup the external image viewer / editor

- My recommendation: IrfanView

- http://www.irfanview.com/

- Supports a lot of image formats

- Provides basic edit functionalities

- Area selection, cut and past, resize, rotation, etc.

Camstudio is the another video capture software with the following features,

- Open Source (GPL)

- Capturing screen motion in the AVI format and the SWF format.

- Original codec (CamStudioCodec10) provided.

Camstudio can be work as follows,

- Run CamStudio

- Click Record button

- Set area on CamStudio

- After a while click Stop button

- Save the file into My Documents

- Toggle the mode to SWF

- Record again and save the file too

- SWFTOOLS

http://www.swftools.org/

- PDF2SWF, JPEG2SWF, AVI2SWF, etc.

- FLVTool2

http://rubyforge.org/projects/flvtool2/

- Setup to output images as files in a folder

- Capture region

- Select menu or Print

- Left-click and drag, then release to capture the area

- Capture window

- Select menu or Alt + Print

- Left-click the target window

- Capture full screen

- Select menu or Ctrl + Print

Capture region has to be designated before the capturing moving picture obviously with the function provided by Camstudio which is shown in Figure 6.

\begin{tabular}{|l||l|l|}
\hline Capture region & \multicolumn{1}{|c|}{ Print } \\
\hline Capture last region & \\
Capture window Alt + Print & \\
Capture full screen Ctrl + Print & \\
\hline Skip image editor & \\
Preferences... & \\
\hline Help & \\
About & \\
\hline Exit & \\
\hline
\end{tabular}

Fig. 6. Designation of capture regions

\section{H. XML based contents}

SCORM meta-tag and XML based database management is key.

http://wareseeker.com/free-scorm-metadata-generator/

- These tags are very important if you want your web pages to be crawled by search engines and play an important role in determining your web site ranking.

- Metadata Generator is the quickest and simplest way to create META tags for your web pages.

- This program guarantees to be the best one out there in its category - with inclusion of all the essential tags for your pages. And the best part is no knowledge of META tags is necessary to use Metadata Generator.

- Just key in the required information and voila, your metadata has been generated.

\section{Mush-up web services}

A web mashup is a new type of web application that uses data and services from one or more external sources (usually from the Internet) to build entirely new and different web applications

Mashup web services are not a web portal. Combining Web service technologies with fresh content, collaborative approaches (such as Web 2.0 technologies), and possibly Web data management and semantic technologies (RSS, RDF). Mashup architecture is shown in Figure 7.

There are some mushup editors as shown below,

\section{Online}

$-\quad$ Yahoo
(http://pipes.yahoo.com/pipes/)

- Microsoft Popfly

(http://www.popfly.com/) died on Aug 24, 2009

- Ubiquity

(http://ubiquity.mozilla.com/)

Application 
- Jackbe (http://www.jackbe.com/)

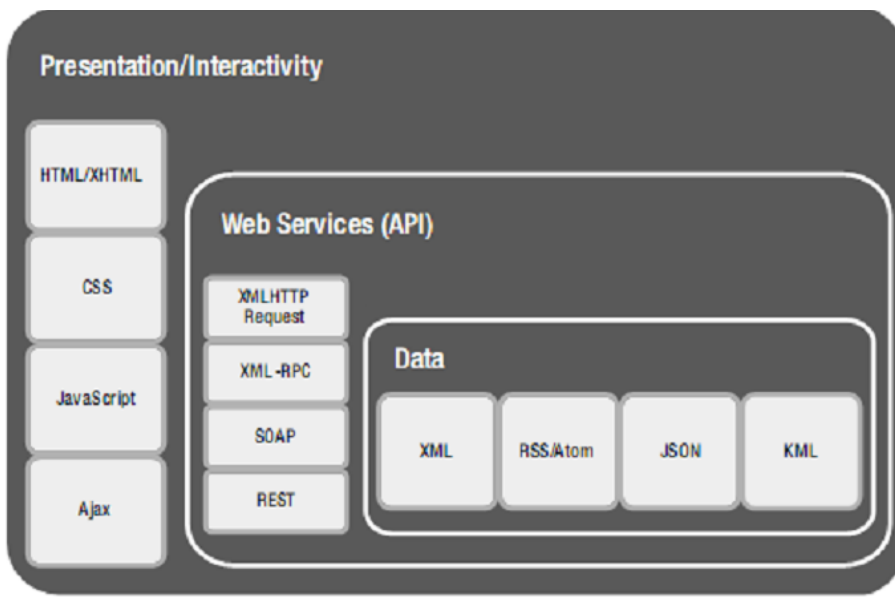

Fig. 7. Mush-up Architecture

Mashup API allows the functions as shown in Figure 8.

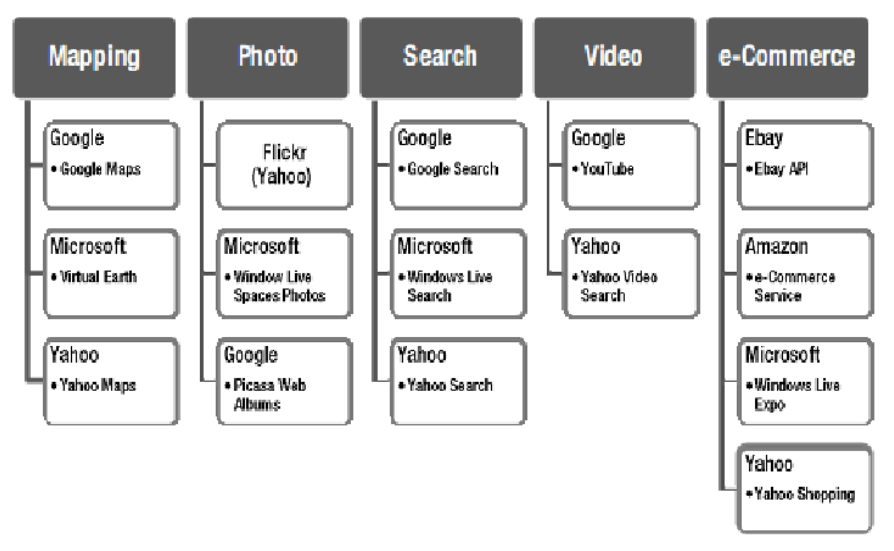

Fig. 8. Available functions for mashup API.

\section{J. Mobile learning}

XHTML MP and WCSS are examples of mashup for mlearning as shown below,

- Client open the application just using standard browser.

- XHTML Mobile Profile \& WAP CSS (WCSS) for Mobile is new standard for develop web application for mobile client (proposed by W3C and OMA)

- Support W3C standard for Mobile Web

In accordance with WiKipedia, mobile learning, mlearning is defined as follows,

- Wikipedia: Learning that happens across locations, or that takes advantage of learning opportunities offered by portable technologies.

- In other words, mobile learning decreases limitation of learning location with the mobility of general portable devices.
- $\quad$ E-learning + mobile computing

- PDA

- Cell phones

- Any small, autonomous and unobtrusive device

There are limitations for mobile devices as follows,

- Smaller Screen Size

- Limit of input key

- Lower memory

- Slower processor speed

- Slower bandwidth rates

- Short battery life

In order to overcome the limitations, the following treatments are required for the m-learning system,

- Format transcoding e.g. XML to XHTML

- http://www.slideshare.net/ : automatic transcoding PowerPoint to Flash

- Scalable Vector Graphics - SVG to GIF

- Scaling (of images as well as video and audio streams),

- Media conversion (e.g. text-to-speech),

- Re-sampling,

- File size compression

- Document fragmentation

- Structure of the typical e-learning content based on XML

- Easily converted to m-learning contents based on the structure described with XML

Thus the contents conversion and display onto mobile devices can be done as shown in Figure 9. 10.

Example of m-learning domain is illustrated in the Figure

There are some content adaptation schemes as follows,

- Proxy based:

- New Mobile Specific Browser

- Opera Mobile, Skyfire

- Server based:

- Server provide specific mobile access: Yahoo

- Mobile, YouTube Mobile, Facebook Mobile, etc 


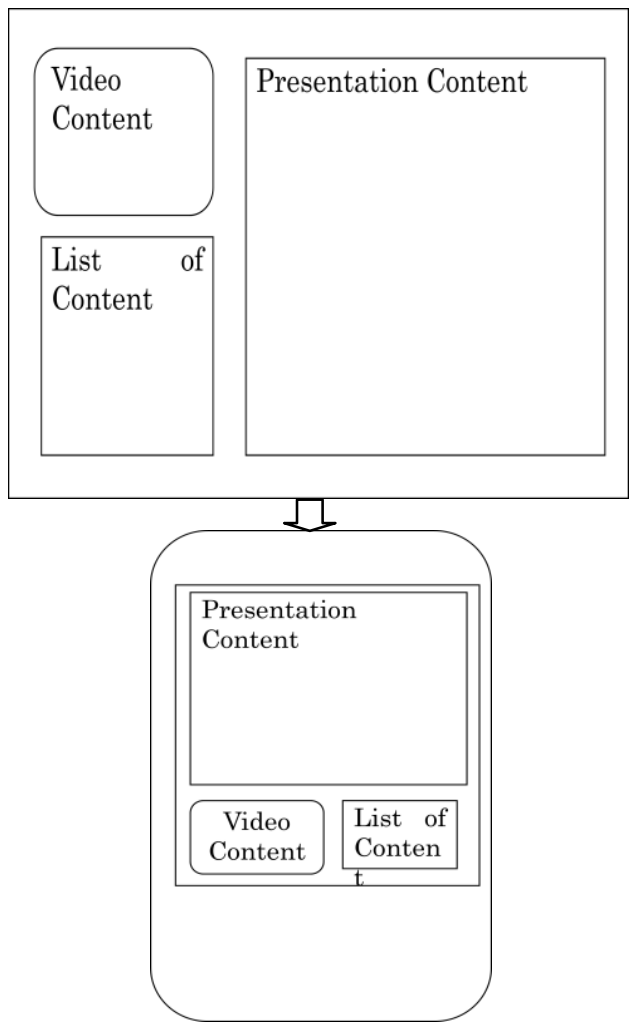

Fig. 9. Content conversion from e-learning to m-learning

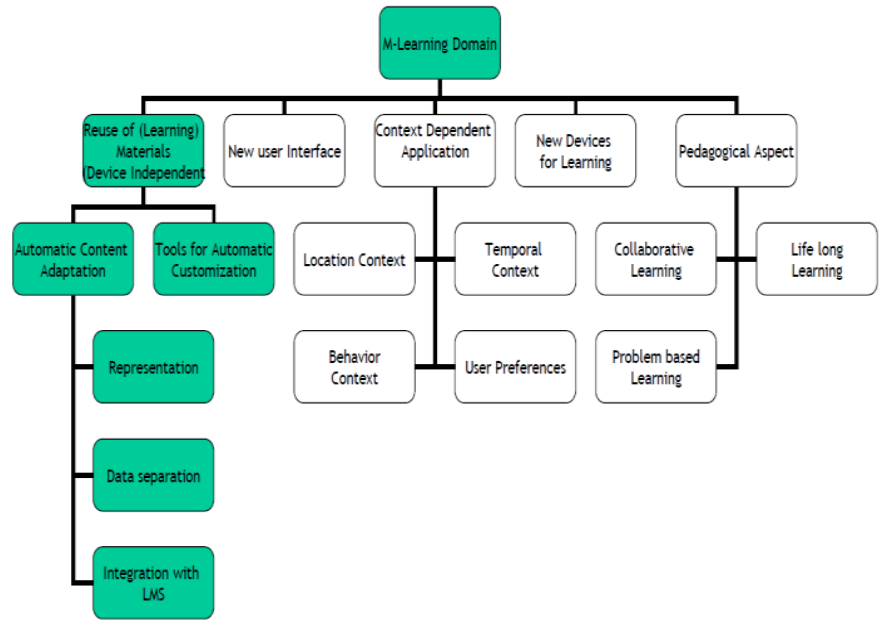

Fig. 10. m-learning domains

There are some W3C standards for m-learning web services as shown below,

- W3C-Deined Default Delivery Context

- Usable Screen Width: 120 pixels, minimum

- Markup Language Support: XHTML Basic 1.1 delivered with content type application/xhtml+xml

- Character Encoding: UTF-8

- Image Format Support: JPEG, GIF 89a
- Maximum Total Page Weight: 20 kilobytes

- Colors: 256 Colors minimum

- Style Sheet Support: CSS Level 1. In addition, CSS Level $2 @$ media rule together with the handheld and all media types

- HTTP: HTTP/1.0 or more recent HTTP 1.1

- Script: No support for client-side scripting

Example of XML tagging is shown in Figure 11.

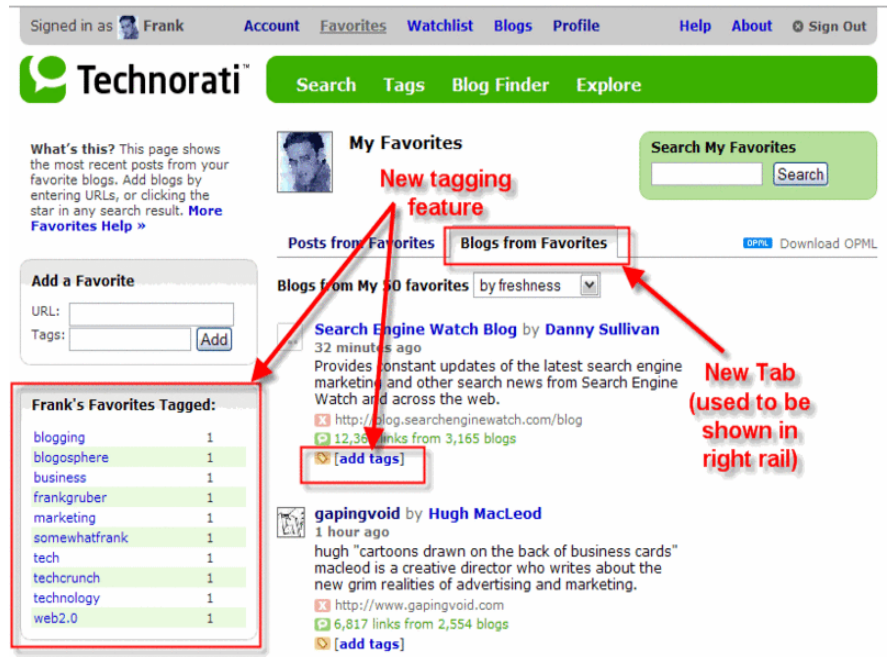

Fig. 11. Example of XML tagging

In the Web 2.0, the followings are available,

- AJAX

- Tagging

- Blogs and blogging

- A list of most "linked-to" blogs

- Really Simple Syndication (RSS)

- Wikis

- Wikis used in business

- Podcasts and Videocasts

\section{EXPERIMENTS}

Implementation of the proposed e-learning, mobile learning system is successfully done. All the functions of the proposed system are confirmed perfectly. Also, it is confirmed the proposed content adaption for displaying e-learning contents on a relatively small size of display of the mobile devices. Mashup e-learning content search engine is validated with a limited web domain with tagging capability.

Figure 12 shows histogram of students' score of achievement tests when before and after the blended learning is conducted. It shows more than 10 points of improvement can be done with the blended learning. 


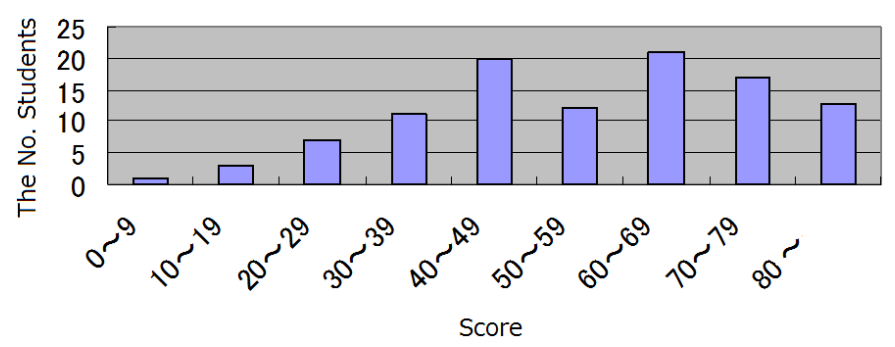

(a)Before

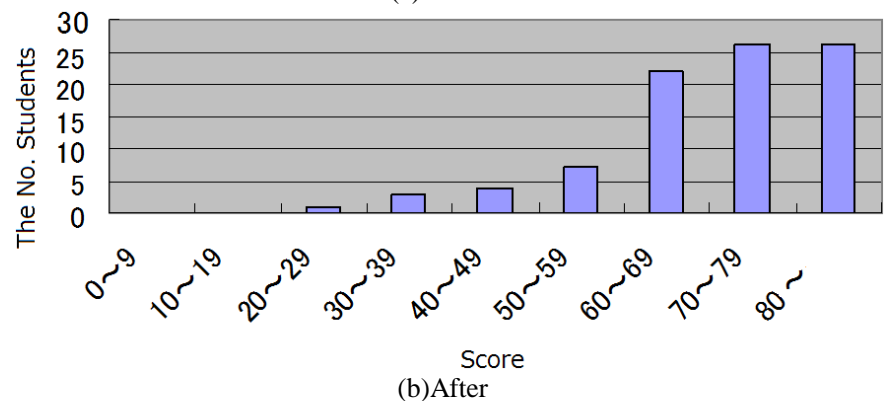

Fig. 12. effectiveness of the blended learning on the applied linear algebra class

\section{CONCLUSION}

At the beginning of the course, readiness of the students has to be confirmed. Blended learning is very useful for that and for improvement their readiness. Through face-to-face lectures with interactive learning, they need to review the contents and exercise is required simultaneously with lecture. Blended learning is applicable for that. After the class, they can re-review the contents through e-learning and m-learning.

The followings are the recommendations for the e-learning and m-learning systems,

- Using SCORM meta-tag, DB management with XML

- Self Instructional Design

- Linkage with class time schedule is effective to the lectures

- Create contents database like the UPO in Japan

- Create portal for free open source software for elearning and m-learning

Table 1 also shows summarized recommendations for creation of e-learning and m-learning contents using FOSS software..

TABLE I. SUMMARY OF THE ZRECOMMENDATIONS FOR E-LEARNING, BLENDED LEARNING AND MOBILE LEARNING SYSTEM

\begin{tabular}{|l|l|l|l|l|}
\hline Environment & $\begin{array}{c}\text { Development } \\
\text { Tools }\end{array}$ & Database & $\begin{array}{l}\text { Programming } \\
\text { Language }\end{array}$ & Web Server \\
\hline Java & Net Beans 6.1 & $\begin{array}{l}\text { MySQL, } \\
\text { PostgreeSQL }\end{array}$ & Java & $\begin{array}{l}\text { Sun Java } \\
\text { Web Server }\end{array}$ \\
\hline Ruby on Rails & Aptana Studio & MySQL & Ruby, Perl & Mongrel \\
\hline Microsoft.net & Visual Studio 8.0 & SQL Server & C\#, VB & IIS 7.0 \\
\hline PHP & Framework? & MySQL & PHP & Apache \\
\hline
\end{tabular}

Acknowledgment

The author would like to thank Dr. Teruya Minamoto and Dr. Mika Otsuki of Saga University as well as Dr. Herman Tolle of Brawijaya University, Indonesia for their efforts through implementation and experiments.

\section{REFERENCES}

[1] M.Oda, S.Oda, K.Arai, CAI system for pronunciation practice in particular for discrimination of $|1|$ and $|\mathrm{r}|$ on WWW site utilizing mouth movements and voices, Journal of Educational System and Information Society of Japan, Vol.17, No.3, pp.162-173, (2000).

[2] Mariko Oda, Seio Oda and Kohei Arai, Effect of pronunciation practice system using capture the mouse movement, Journal of Educational Engineering Society of Japan, vol.26, No.2, 65-75, 2003

[3] K.Arai, Mayumi Inokuchi, Web based e-learning system allowing BBS, chatting with equation representation together with annotations, Report of Science and Engineering Faculty Saga University, 36、1、1-8、 2007

[4] K.Arai, Hiroshi Yoshida, e-learning system with users' confidence level evaluations through voice input system, Report of Science and Engineering Faculty Saga University, 36、1、39-44、2007

[5] Kohei Arai,Herman Tolle, Model based content adaptation of composite e-learning content for delivering to mobile learners, International Journal of Computer Theory and Engineering, 3, 3, 382-387, 2011

[6] K.Arai, T.Herman, E-learning document search method with supplemental keywords derived from keywords in meta-tag and descriptions which are included in the header of the first search result, International Journal of Advanced Computer Science and Applications, 3, 4, 99-104, 2012.

[7] K.Arai, Method for leaning efficiency improvements based on gaze location notifications on e-learning content screen display, International Journal of Advanced Research in Artificial Intelligence, 1, 3, 1-6, 2012.

[8] K.Arai, M.Oda, Effect of pronunciation practice system based on personalized CG animations of mouth movement model, International Journal of Advanced Computer Science and Applications, 3, 6, 125-130, 2012.

[9] K.Arai, E-learning system which allows students' confidence level evaluation with their voice when they answer to the questions during achievement tests, International Journal of Advanced Computer Science and Applications, 3, 9, 80-84, 2012.

[10] K.Arai, Free Open Source Software: FOSS based GIS for spatial retrievals of appropriate locations for ocean energy utilizing electric power generation plants, International Journal of Advanced Computer Science and Applications, 3, 9, 95-99, 2012.

[11] Kohei Arai, Anik Nur Handayani, Predicting quality of answer in collaborative Q/A community, International Journal of Advanced Research in Artificial Intelligence, 2, 3, 21-25, 2013.

[12] Kohei Arai, Anik Nur Handayani, E-learning system utilizing learners' characteristics recognized through learning process with Open Simulator, International Journal of Advanced Research in Artificial Intelligence, 2, 4, 8-12, 2013.

\section{AUTHORS PROFILE}

Kohei Arai, He received BS, MS and PhD degrees in 1972, 1974 and 1982, respectively. He was with The Institute for Industrial Science and Technology of the University of Tokyo from April 1974 to December 1978 also was with National Space Development Agency of Japan from January, 1979 to March, 1990. During from 1985 to 1987, he was with Canada Centre for Remote Sensing as a Post Doctoral Fellow of National Science and Engineering Research Council of Canada. He moved to Saga University as a Professor in Department of Information Science on April 1990. He was a councilor for the Aeronautics and Space related to the Technology Committee of the Ministry of Science and Technology during from 1998 to 2000 . He was a councilor of Saga University for 2002 and 2003. He also was an executive councilor for the Remote Sensing Society of Japan for 2003 to 2005. He is an Adjunct Professor of University of Arizona, USA since 1998. He also is Vice Chairman of the Commission "A" of ICSU/COSPAR since 2008. He wrote 30 books and published 478 journal papers. 